\title{
An Equilibrium Analysis of Marriage, Divorce and Risk-Sharing
}

\author{
By Dan Anderberg \\ University of Stirling, CEPR and CESifo
}

J anuary 7,2002 


\title{
An Equilibrium Analysis of Marriage, Divorce and Risk-Sharing
}

\author{
A bstract \\ This paper considers marriage, divorce and reciprocity-based cooperation by couples in the \\ form of sharing of earnings-risk. While risk sharing is one bene..t to marriage it is also limited \\ by divorce risk. With search in the marriage market there may be multiple equilibria dixering \\ not only in family formation and dissolution patterns but also in the role of marriage in pro- \\ viding informal insurance. Publicly provided earnings-insurance, despite potential equilibrium \\ multiplicity, is shown to axect family formation and ..nancial cooperation monotonically. \\ K eywords: Marriage, Divorce, Risk-Sharing \\ J EL Classi..cation: J 12, D11, D83, H30
}




\section{Introduction}

Marriage as an institution has changed dramatically in the recent decades. The patterns are the same in many countries: age at ..rst marriage has increased, cohabitation as a format for partnership has become more popular; but perhaps more controversial than any other indicator of change is the rapid increase in the number of divorces.

Several factor are likely to have contributed to this development, such as e.g. changing labour market conditions, contraceptives, and changes in the legislation surrounding divorce. However, many would also point out the potential role played by the welfare states. Indeed, paralleling the rapid growth of divorce rates has been the expansion of welfare state arrangements in most developed countries: a wide range of bene..t systems, including unemployment insurance, bene.ts to lone parents, housing bene..ts etc. are likely to make it easier for individuals to cope on their own, and can therefore be expected to axect family formation- and dissolution patterns.

Taking a negative view it is conceivable that a main exect of public bene.ts and transfers is to crowd out private informal transfers and to make couples less willing to "stick it out". Then if there are negative externalities associated with divorces - most notably on the children - there is a case for adopting a sceptical view. However, welfare state arrangements may also allow individuals to gain "..nancial independence" from their partners. Partnerships might then be formed and maintained, not for ...nancial security, but for "love".

The purpose of this paper is to suggest a simple framework for studying marriage, divorce and ..nancial cooperation. A fundamental aspect of ..nancial cooperation between partners is that it cannot, in general, be assumed to be legally enforced. Hence, more speci..cally, the focus of the paper is on the consequences of reciprocity-based ..nancial cooperation in the form of voluntary sharing of earnings risk. The lack of legal enforcement is shown to have a number of potentially important exects.

Since risk sharing is a bene..t to marriage, large responses to changes in welfare policy may obtain both in terms of marriage and divorce behavior and in terms of cooperation. By increasing the utility associated with being single (and hence the utility associated with divorce), publicly provided earnings insurance directly reduces the cooperation that a married couple can sustain; this in turn lowers the bene.t to being married, further increasing the divorce risk, and again lowering the cooperation that can be sustained, and so on. A further "multiplier exect" can obtain through search complementarities in the marriage market: when an individual joins 
the marriage market, this increases the probability of every other single individual of ..nding a new partner. Hence, if public earnings-insurance induces some individuals to choose singlehood rather than marriage, this in turn makes divorce even more attractive for others, leading to further divorces and less cooperation.

The ..rst part of the paper sets up the basic model with a single couple who can cooperate ..nancially, but who also have the option of divorcing. Match-quality varies over time and divorce occurs when the net bene.t from remaining married becomes negative. The earnings of each partner łuctuate and the couple can smooth their individual consumption paths through voluntary transfers. The model is then closed by the introduction of a marriage market with search. Given "agglomeration" in search, multiple equilibria exhibiting qualitative dixerences may occur. While one equilibrium may exhibit a low "turnover" in the marriage market and a high degree of ..nancial cooperation, another equilibrium will exhibit high "turnover" and less risk-sharing by partners. A natural question is which is better: a high- or a low-turnover equilibrium? This answer to this question is argued to be ambiguous when there is reciprocitybased cooperation.

The exects of publicly provided earnings-insurance are then examined. Public insurance is shown to have a monotonic exect on family formation patterns (though the possibility of multiple equilibria implies that levels may vary across economies). The analysis suggests that welfare spending will increase the fraction of single individuals, generally increase the rate of partnership dissolution, and possibly also the rate of partnership formation. The model makes no distinction between marriage and cohabitation, but in so far as divorce rates rełect partnership dissolution rates, the aggregate divorce rate is predicted to be positively associated with social spending.

Do these predictions make sense empirically? How do partnership formation and dissolution patterns vary with welfare spending in a cross-country comparison? Some rough indications can be obtained from Fig 1; the horizontal axis in each display measures social spending as percentage of GDP (in 1994). Focusing initially on entry and exit from ..rst partnerships, Display 1 shows the fraction of "..rst partnerships that dissolve within ...ve years". Display 2 shows the fraction of individuals who "enter a ..rst partnership before the age of 25". Display 3 then shows the fraction individuals aged 35-39 who are "without current partners". Display 4 shows the aggregate divorce rate. Though the patterns are not overly strong, all displays 
suggest monotonic relations to welfare spending. ${ }^{1}$

FIG 1.

The model also predicts that publicly provided insurance will reduce ..nancial cooperation by partners. Testing this implication involves comparing equilibrium outcomes across marriage markets with a focus on market-level variables. A tentative analysis of this prediction, using international survey data, is presented towards the end of the paper.

The current paper draws on number of dixerent strands of literature. The literature on marriage and divorce was pioneered in the seminal papers by Becker (1973) and B ecker, Landes and M ichael (1977). The literature on marriage and divorce is surveyed in Weiss (1997). There is a growing literature on marriage markets with search. An early contribution is M ortensen (1988).

Recent work on has pointed out that inec cient allocations of family resources may obtain (see L undberg and Pollak, 1994, 2001). The standard rationale for assuming away inec ciencies - e.g. by employing cooperative game theory or "unitary" models - is the belief that ed cient allocations can be sustained through repeated interaction. However, not even repeated interaction can guarantee complete cooperation, particularly when there is a risk that the interaction may terminate. I model repeated interaction with (stochastic) endogenous break-ups and argue that inec cient risk sharing may obtain.

Models with marriage market search have recently been used to consider a wide range of issues. E.g. Burdett and Coles (1997) consider assortative mating. Burdett et al. (1999) consider how search while married can generate equilibrium multiplicity. Drewianka (2000) uses a model similar to the current one - albeit with a focus on relation-speci..c investments - to consider recent proposals for reforming the legislation surrounding marriage and divorce. Chiappori and Weiss (2000) considers a model with divorce settlements, and argue that contract externalities arise since the identities of any future partners are unknown at the time of the divorce. Burdett and Ehrmich (2001) consider out-of-wedlock fertility using a search-framework.

\footnotetext{
${ }^{1}$ Social spending, obtained from the OECD Social Expenditure Database 1980-1997, includes old-age cash transfers, disability cash bene..ts, occupational injury and disease, sickness bene..ts, family cash bene..ts, unemployment compensation, early retirement bene..ts, as well as expenditures on health and housing. The data on partnership formation, dissolution and partnerships is from UNECE Population Activities Unit (and refer to the early- to mid 90s), supplemented with data from $N$ ational Survey of Families and Households for the US, as reported in Bumpass and Sweet (1989). A ggregate divorce rates are from the UN 1997 Demographics Yearbook.
} 
A rapidly growing literature - too extensive to be summarized here - considers the exect of welfare policies on family structure and welfare. Some of this literature is closely linked to the wider literature on intergenerational mobility. A very promising branch of this literature seeks to build comprehensive models of marriage, divorce, fertility, and human capital investments which can be used for public policy purposes. See in particular Aiyagari et al (2000), Greenwood et al. $(2000 a, b)$. Compared to these models, our aim is more modest and focuses more particularly on one aspect: the implications of reciprocity-based cooperation between partners.

Hess (2000) in an interesting recent study uses micro-level data to indirectly infer the importance of risk-sharing bene.ts by considering income streams and subsequent divorce behavior.

The current model also draws on the literature on self-enforcing risk-sharing. T wo early contributions to this literature are K imball (1988) and Coate and Ravallion (1993). Kocherlakota (1996) and Ligon et al. (1997) showed that optimal self-enforcing risk-sharing arrangements are generally not stationary (even when the underlying income-generating process is). Ligon et al. (1998) introduced savings, and Foster and Rosenzweig (2000) introduced altruism between the agents sharing risk. The current paper contributes to this literature by allowing for endogenous stochastic formation and breakups by partners sharing risk; on the other hand only "stationary" risk-sharing arrangements are considered.

The paper is organized as follows. Section II sets up the basic risk-sharing model. Section III studies the risk-sharing and divorce behavior of a given married couple. Section IV considers the exect of marginally extending public insurance while still ignoring family formation decisions (marriage and remarriage). Section V introduces the marriage market and Section VI considers the features of steady state equilibria. Section VII discusses a number of extensions while Section VIII presents a brief empirical illustration. Finally Section IX concludes.

\section{The Risk-Sharing M odel}

This section describes the basic risk-sharing model. A marriage market will be introduced in Section $V$, but for now the focus is on a given married couple. In order to keep the analysis tractable the model abstracts from a number of aspects, most notably relations-speci... investments and idiosyncratic earnings-expectations. This leaves risk-sharing as the key reason for transfers between spouses, and it also allows us to analytically derive implications of publicly provided insurance. Some possible extensions are, however, discussed in Section VII.

Thus consider a given married couple; the current state of the marriage is described by a 
match-quality variable. This variable captures feelings of "love", and may also include other ..nancial gains to marriage except risk-sharing. To capture the notion that "love comes and goes" the match-quality evolves stochastically as a simple Markov chain.

In each period, each partner receives a random income; for simplicity incomes are assumed to be uncorrelated across time and individuals. The couple can smooth their individual consumption paths through voluntary transfers. Transfers between the partners are, however, not legally enforced; hence they must be supported by expected reciprocity.

Since the couple may break up, divorce risk limits the sustainable levels of cooperation. Note, however, that since risk-sharing is also a bene.tt to marriage, the prospect of risk-sharing also infuences the divorce decision. Each partner always has the option of walking away from the marriage ("no-fault divorce") and will do so when the net bene.t to continued marriage falls short of the bene..t from divorce. ${ }^{2}$

\section{M atch Quality}

Let $\mu 2 \mathrm{R}$ denote "match-quality", which evolves stochastically. For simplicity - and to focus on transfers between partners as a risk-sharing device - partners are assumed always to agree on the match-quality. There is a ..nite set of match qualities, $f=f \mu_{0} ;: .: ; \mu_{N} g$; the set $f$ is ordered increasingly: $\mathrm{j}>\mathrm{i}$ implies $\mu_{\mathrm{j}}>\mu_{\mathrm{i}}$. Let $1 / \mathrm{uj}_{\mathrm{j}}$ denote the probability that the match-quality will be $\mu_{\mathrm{j}}$ next period given that it is $\mu_{\mathrm{i}}$ in the current period.

A ssumption 1. The Markov transition matrix $i=f 1 / 4 ; j g_{i ; j=0}^{N}$ is regular and satis..es the following stochastic dominance condition: $P_{k=0}{ }_{j / 4 k}$ is weakly decreasing in $i$ for every $j$.

The stochastic dominance property ensures that a good match-quality tomorrow is more likely the better is the match-quality today; it thus ensures a degree of "persistency" of good and bad times.

\section{Incomes and Consumption}

Utility of consumption, $u(\phi$, is increasing, concave and bounded. In each period each individual earns an income which is randomly drawn from a ..nite set of possible income levels

\footnotetext{
${ }^{2}$ The literature has put forward the idea that divorces are ec cient in the sense that they occur when the utility from continued marriage falls short of the sum of the husband's and wife's outside opportunities. This eф ciency result requires transferable utility and symmetric information (see Becker (1991) and Peters (1986)). In the current model outside opportunities are symmetric and common knowledge.
} 
(C) $\mathrm{y}^{1 ;} ; \ldots ; \mathrm{y}^{\mathrm{M}} \stackrel{\mathrm{a}}{ }$. Earnings realizations are independent across time and individuals; the probability of an individual earning $y^{i}$ in any period is denoted $g_{i}$. There are no savings.

\section{Risk Sharing}

Three assumptions about the risk-sharing will be made, all of which require some comments. First, risk-sharing is assumed to occur only between individuals who are currently married all other relationships are assumed to be either too unstable or not to lend themselves easily to risk-sharing. Second, recent work on risk-sharing (in environments without breakups) has shown that it may be optimal to condition current transfers on past transfers. ${ }^{3}$ However, since the current analysis introduces endogenous breakups, it is natural to simplify in another dimension; thus transfers are assumed to be conditioned only on current income and matchquality. Third, love does not come in the form of "altruism" - only in the form of enjoyment of being together. Allowing the couple to care about each other's consumption (or utility) is known to axect self-enforceable risk-sharing arrangements in two ways (see e.g. Foster and R osenzweig, 2000). First it makes an individual more willing to make transfers to his/ her partner, simply out of concern for the other person's well-being. This relaxes the incentive constraints (see below) and enables more transfers. However, there is also a second exect, viz. an altruistic individual will voluntarily make transfers even when there is no implicit cooperation; this limits the threat of non-cooperation, which in turn tightens the incentive constraints. A voiding the altruism formulation thus simpli..es the analysis, and also avoids making assumptions about how altruistic feelings are axected by the act of divorce.

Given the current match-quality $\mu$ and consumption $c$, the current utility is simply $u(c)+\mu$ An individual's consumption c may deviate from his/ her current income y due to transfers to/ from the partner. The partners agree on ..nancial cooperation on a period-by-period basis - no long-term commitment is possible. This takes the following form: prior to learning the current income realizations, the partners agree that if one of them receives an income $\mathrm{y}^{\mathrm{m}}$ and the other an income $\mathrm{y}_{\underline{L}}^{\mathrm{k}}$, where $\underline{\mathrm{y}}^{\mathrm{m}}>\mathrm{y}^{\mathrm{k}}$, the former should transfer a non-negative fraction, $\mathbb{R}_{\mathrm{mk}}$, of the dixerence ${ }^{-} \mathrm{y}^{\mathrm{m}} \mathrm{i} \mathrm{y}^{\mathrm{k}^{-}}$to the latter. Transfers are assumed to be symmetric (i.e. not depending on who receives $\mathrm{y}^{\mathrm{m}}$ and who receives $\mathrm{y}^{\mathrm{k}}$ ). A risk-sharing agreement is thus an agreement, for one period, on how much to transfer, for each pair of asymmetric income realizations, from the partner with the higher income to the partner with the lower income. It

\footnotetext{
${ }^{3}$ See K ocherlakota (1996), Ligon et al. (1997) and Attanasio and Rios-R ull (2000).
} 
is therefore fully described by a vector ${ }^{\circledR}$,

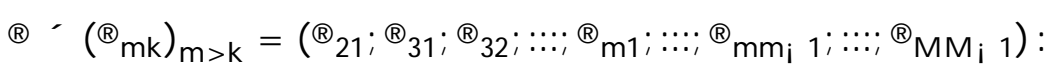

If half the earnings-dixerence is transferred, $\mathbb{R}_{\mathrm{mk}}=1 \Rightarrow$, the partners enjoy the same consumption; larger transfers will never be relevant. ${ }^{\circledR}$ can therefore be restricted to be in the set $A^{\prime}[0 ; 1 \Rightarrow]^{M(1, M)=2}$.

The agreement $®$ determines each partner's expected utility from consumption in the current period; denote this expected utility $\grave{A}(\AA)$,

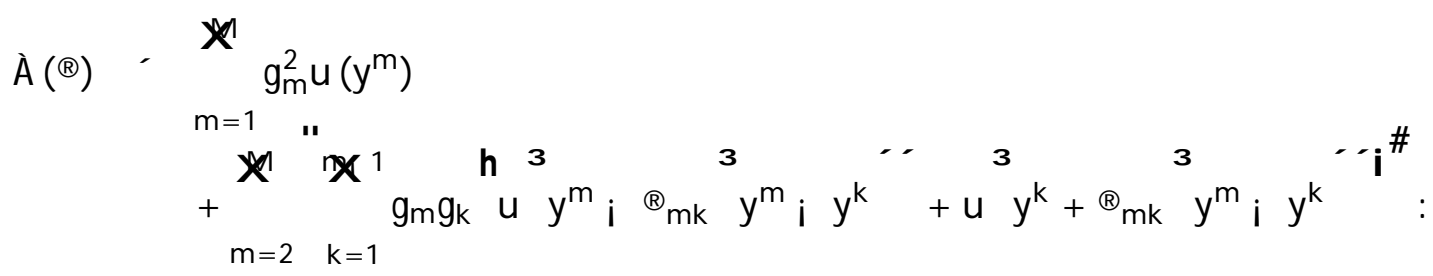

Note that $\hat{A}(\mathbb{R})$ is maximized when all $\mathbb{R}_{\mathrm{mk}}=1=2$; this simply refects the fact that it would be optimal for the partners to share risk completely in each period. This may, however, not be incentive compatible, and in general the sustainable risk-sharing ${ }^{\circledR}$ will depend on the current match-quality.

\section{The Decision Problem Facing a M arried Couple}

For now the value of being single - denoted V (s) - will treated as exogenous (and the same for both partners); later on $\mathrm{V}$ (s) will be endogenized by the introduction of a marriage market. The focus will be on steady states; hence time will not be included as argument in the Bellman equations.

\section{Incentive Compatible Plans}

The timing within each period is as follows: ..rst the couple learns the current match-quality $\mu$ Based on that observation they decide whether to stay together or to divorce. If they stay together they also decide on a risk-sharing agreement $®$ for that period; ..nally earnings are realized. In the beginning of each period the partners are identical and are assumed to choose among plans so as to maximize their common discounted stream of future expected utilities. However, some risk-sharing agreements may not be incentive compatible. It is therefore 
necessary to consider the consequences of a partner failing to make an expected transfer. A failure to make an expected transfer is assumed to lead to an immediate divorce. ${ }^{4}$

A partner who is called upon to make a transfer must therefore be better ox making the expected transfer - given that this leads to continued marriage - than unilaterally triggering divorce; since the incentive constraints are forward-looking and seeing as the transitions between match-qualities follow a Markov chain, the couple faces identical decision problems in any two periods where their match-quality is the same. A straightforward dynamic programming approach can therefore be adopted to characterize the couple's optimal decision. For each $\mu 2 \mathrm{f}$, de..ne $\mathrm{V}(\mu)$ as the maximal (common) discounted stream of future expected utility given the current match-quality $\mu$; also let $\pm 2(0 ; 1)$ denote the discount factor. Since the couple can either divorce - which would give the value $\mathrm{V}(\mathrm{s})$ - or stay together, $\mathrm{V}(\Phi$ must satisfy the following optimality equation: for all $\mathrm{i}$,

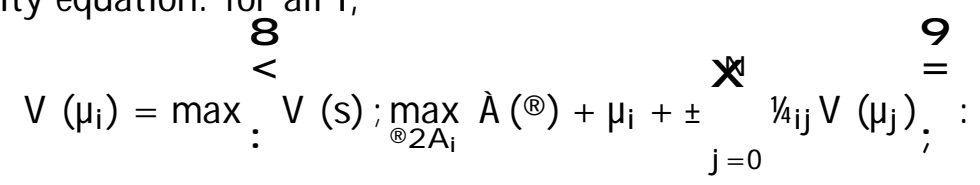

The ..rst term in the large brackets represents the value of breaking up. The second term represents the value of staying together; associated with this option is a choice of risk-sharing agreement $\AA$ If the couple decides to stay together ${ }^{\circledR}$ must also be such that no one will be better $0 x$, at any pair of income realizations, by unilaterally causing divorce through failing to make the agreed on transfer. The set of incentive compatible or "self-enforceable" risk-sharing agreements, $A_{i}$ - a subset of the set of all possible risk-sharing agreements $A$ - generally depends on the current match-quality $\mu_{i}$. In particular $A_{i}$ can be expected to be smaller the worse is the current match-quality, a conjecture that will be veri..ed below.

The self-enforceability constraints are forward-looking and can be formulated as follows: the risk-sharing agreement $\circledast$ is self-enforcing in state $\mu_{i}$, i.e. $\circledast 2 A_{i}$, if and only if $\circledast 2 A$ and, for all $m>k$ such that $\mathbb{R}_{\mathrm{mk}}>0,5$

$$
u^{3} y^{m} i \Re_{m k}^{3} y^{m} i y^{k}+\mu_{i}+ \pm_{j=0}^{N} 1 / \mu^{N} V\left(\mu_{j}\right), u\left(y^{m}\right)+ \pm V(s):
$$

The left hand side is the utility associated with making the prescribed transfer while the right hand side is the utility of deviating, unilaterally triggering divorce. Since the set of self-enforcing

\footnotetext{
${ }^{4} \mathrm{~T}$ he literature on self-enforcing risk-sharing usually assumes that there is a reversion to the static no-transfer equilibrium. This captures the idea of broken trust.

${ }^{5}$ It is implicitly assumed that the deviating spouse loses the match-quality in the deviating period; this assumption is not crucial.
} 
risk-sharing agreements depends on the current match-quality $\mu$, so will in general the chosen ${ }^{\circledR}$, thus let $\mathbb{R}(\mu)$ denote the risk-sharing agreement adopted in state $\mu$ Equation (2) together with (3) de.nes $V(\varnothing$ as the solution to a functional equation. Next it is demonstrated that, under a su $\phi$ cient condition, the functional equation has a unique solution and that $\mathrm{V}$ ( $\phi$ has some expected properties.

\section{Risk-Sharing and Divorce}

Since match-quality has a direct value it is a natural conjecture that the couple is better ox the higher is the current match-quality. Since match-quality has a degree of persistence, and since a low enough match-quality can be expected to trigger divorce, a high current match-quality should be associated with a low future divorce risk. This in turn facilitates more cooperation. Thus it seems natural to conjecture that a high current match-quality is associated with a high current level of ...nancial cooperation. This should further contribute to making the couple better ox when the current match-quality is high.

Note however that since the scope for risk-sharing increases when the divorce risk decreases, staying together almost becomes self-justifying. To ensure uniqueness, a condition is imposed. It should be stressed that the condition, which imposes an upper bound on the value of risksharing, is only suф cient and, in most cases, probably far from necessary. ${ }^{6}$ Thus assume:

A ssumption 2. (A bound on the value of risk-sharing). The following inequality holds:

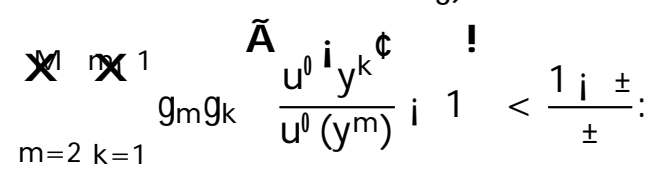

Consider e.g. the case where there are only two income levels, $\mathrm{y}^{1}$ and $\mathrm{y}^{2}$. The left hand side increases in the income dixerence ${ }^{-} \mathrm{y}^{2} \mathrm{i} \mathrm{y}^{{ }^{-}}$and in risk-aversion; moreover $g_{1} g_{2}$ is maximized when the income variance is maximized. The inequality then places an upper bound on the weight placed on future utility, \pm Suppose e.g. $u^{0^{i} y^{1}}=2 u^{0^{i}} y^{2^{\phi}}$ and $g_{1}=g_{2}=1 \Rightarrow$; the condition then requires that $\pm<0: 8$ while for other $g_{1}$ and $g_{2}$ the critical \pm is closer to unity.

The ..rst conjecture can now be veri..ed: the higher is the current match-quality, the better ox is the couple.

\footnotetext{
${ }^{6}$ Indeed, it is a suф cient condition for Equation (2) and (3) to identify a mapping which satis..es Blackwell's suф cient condition for a contraction mapping, which in turn is suф cient the functional equation to have a unique solution (see the A ppendix for details.)
} 
$\mathrm{Cl}$ aim 1 . The value function $\mathrm{V}(\phi$ exists, is unique, and is weakly increasing in $\mu$

Proof. See the A ppendix.

K nowing that $\mathrm{V}(\phi$ is increasing is suф cient to establish a cut-ox rule for the divorce decision. Suppose that the variability in $\mu$ is large enough that there will be some matchqualities where the couple stays together and some where they break up; then by de..ning $q^{\prime} \max f \mu 2 \mathrm{fjV}(\mu)=V(s) g$ it follows that the couple stays together only as long as $\mu>A$ Combining the observation that divorce occurs at low match-qualities with the monotonicity of $\mathrm{V}(\phi$, and invoking the assumption that a high current match-quality is associated with high future match-qualities (A ssumption 1) it can also be veri..ed that risk-sharing is an increasing function of the current match-quality.

Cl aim 2. Given that the couple have not divorced prior to period $t$, the level of risk-sharing in

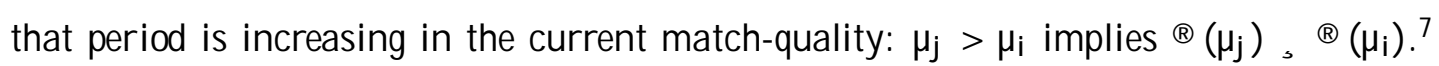

P roof. See the A ppendix.

The main results from this section is thus that the match-quality underlies both the divorce decision and the risk-sharing decision. The better is the current match-quality, the more the partners will cooperate ..nancially, and, due to the persistence of the match-quality lower is the risk of imminent divorce. The model thus makes the very natural prediction that more current cooperation is negatively associated with future divorce risk.

\section{A Partial Equilibrium Exect of Formal Insurance}

This section provides, by ignoring the possibility of re-marriage, a partial equilibrium analysis of the impact of public insurance on divorce behavior and risk-sharing. Publicly provided insurance is shown to make the couple more prone to divorce in the sense that it expands the set of match-qualities where they divorce.

T wo forces are at work. First, since formal insurance is more valuable to an individual who has no other insurance available, there is direct positive exect of formal insurance on the probability of divorce: intuitively formal insurance implies that an individual can axord to leave a relationship that has gone sour even if that means forgoing future access to informal risk-sharing. However, increasing the utility of being going-it-alone also reduces the cooperation

\footnotetext{
${ }^{7} \mathbb{B}\left(\mu_{\mathrm{j}}\right), \mathbb{B}\left(\mu_{\mathrm{i}}\right)$ if every element in $\mathbb{B}\left(\mu_{\mathrm{j}}\right)$ is at least as large as the corresponding element in $\mathbb{B}\left(\mu_{i}\right)$.
} 
in states where the self-enforceability constraint binds, which further decreases the value of continued marriage.

To demonstrate these exects formally it is convenient to focus on the case where there are only two possible income levels $\mathrm{y}^{1}$ and $\mathrm{y}^{2}$; this simpli..es the analysis and avoids making assumptions about the form of the publicly provided insurance: as long as formal insurance is based only on current individual income it reduces to a net transfer from individuals with high income, $\mathrm{y}^{2}$, to individuals with low income, $\mathrm{y}^{1}$. Thus let $i$ denote the tax imposed on individuals with a current high income. By budget balance, the transfer to low-income individuals must equal $\left(g_{2}=g_{1}\right) i$. Hence, given $i$, the net incomes are

$$
y^{2}=y^{2} \text { i } i ; \quad \text { and } \quad y^{1}=y^{1}+\frac{g_{2}}{g_{1}} i \text {. }
$$

Consider then a marginal expansion of formal insurance from a situation with less than full insurance (i.e. initially $\varphi^{2}>e^{1}$ ). Note that, with formal insurance included, and using $M=2$, the de..nition of the within-period expected consumption utility, $\grave{A}(\phi$, reduces to:

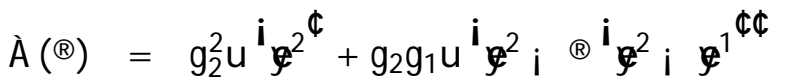

$$
\begin{aligned}
& +g_{1} g_{2} u^{i} \varphi^{1}+\circledR^{i} \varphi^{2} i \varphi^{1 థ}+g_{1}^{2} u^{i} \varphi^{1} \text { : }
\end{aligned}
$$

Note also that the subscript on $®$ has been dropped since, in the case with just two income levels, a risk-sharing agreement $®$ reduces to a scalar.

To emphasize the impact of $i$, we can include $i$ as a formal argument for the critical matchquality where divorce occurs, $\boldsymbol{Q}(\dot{i})$. The main result is that $\boldsymbol{Q}(\dot{i})$ is monotonic in $i ;$ however, as the proof demonstrates, public insurance also crowds out private transfers: increasing $i$ (weakly) decreases the absolute informal transfer (i.e. $\left(\mu_{i}\right)^{i} q^{2} i e^{1}$ ) in each state $\mu_{i}$ where the couple remain married.

$\mathrm{Cl}$ aim 3. Suppose that $\mathrm{M}=2$ and that remarriage is not possible. Then $\boldsymbol{Q}(\dot{ })$ is non-decreasing in $i$ and the informal income transfer in each state is decreasing in $i$.

Proof. See the A ppendix.

Publicly provided insurance is often suspected of crowding out private insurance coverage. B ut formal insurance can also crowd out less formal forms of insurance that occur within families. This was noted e.g. by Berry-Cullen and Gruber (2000) who argue that the existence of formal unemployment insurance may be a potentially important reason for why the literature on the 
so-called added-worker exect typically ..nds relatively small exects. The current model focuses on direct transfers between partners as opposed to compensating income streams.

Yet the analysis suggests that crowding out can be pervasive: expanding formal insurance may crowd out informal risk-sharing at a high rate. The direct exect of public insurance is to make singlehood relatively more attractive by reducing the associated consumption variance; this exect reduces the sustainable level of cooperation for couples that remain married (by tightening the self-enforceability constraints). This in turn reduces the bene..t to marriage, further increasing the relative attractiveness of singlehood, and so on. ${ }^{8}$

\section{Family Formation}

The analysis in the previous section was only of a partial equilibrium nature in that family formation was ignored. To capture the feedback exect that can obtain through search complementarities in the marriage market, the model is now expanded to include family formation.

\section{The M arriage M arket}

Consider an economy with a continuum (of unit measure) of in..nitely lived identical individuals. Each individual is either married or single; let S $2[0 ; 1]$ denote the number of single individuals. Single individuals search for new partners, and Á(S) denotes the probability of ..nding a potential partner during a period of search (for simplicity a searching individual meets at most one potential partner during a period of search). The matching rate Á depends non-negatively on the number of searching individuals $S$, that is $A^{0}(\phi, 0$ ("agglomeration"). Search is costless; however, a single individual has no one to share income with. Hence the expected utility during a period of search is $\grave{A}(0)$.

Potential partners meet at the end of a period of search; at the beginning of the next period they learn their initial match-quality. Based on the initial match-quality two newly matched individuals decide whether to form the partnership or to continue to search. Since the Markov process for the match-qualities is regular it has a limiting distribution $F$ de.ned on $f$. The density of $F$, denoted $f$, is strictly positive on $f$ and is uniquely de.ned through the following

\footnotetext{
${ }^{8} \mathrm{Di}$ Tella and M acCulloch (1999) and Attanasio and Rios-R ull (2000) have recently considered the crowding out exect of formal insurance on voluntary risk-sharing (although without considering breakups).
} 
equations:

$$
f\left(\mu_{i}\right)=\sum_{k=0}^{N} 1 / k i f\left(\mu_{k}\right) ; \text { and } \sum_{i=0}^{N} f\left(\mu_{i}\right)=1 .
$$

The distribution $F$ is a natural candidate for the distribution of initial match-qualities. Since I assume that there are no speci..c marriage- or divorce costs, two newly matched individuals are in exactly the same position as a couple, with the same match-quality, that have been married for any arbitrary number of periods. Hence they will all adopt the same critical match-quality $\not$ when making their partnership formation/ dissolution decisions.

\section{The Choice of Critical M atch-Quality}

When remarriage is possible, the value of starting a period as single, $\mathrm{V}(\mathrm{s})$, is endogenous. Formally, there is, in addition to (2) and (3) characterizing $\mathrm{V}(\mu)$, an equation for $\mathrm{V}(\mathrm{s})$. This equation has the following form:

$$
V(s)=\grave{A}(0)+ \pm{ }_{:}^{8} \hat{X}_{j=0}^{N} f\left(\mu_{j}\right) V\left(\mu_{j}\right)+(1 ; \quad A ́) V(s) \stackrel{9}{=}
$$

where $\hat{A}(0)$ is the current expected utility and the bracketed term is the value of the continuation; Áf $(\mu)$ is the probability that the individual will ..nd a new partner with initial match-quality $\mu$ and with probability 1 i Á no new potential partner is located during the period. The matching probability Áis taken as given by a searching individual even though it is endogenously determined by the aggregate behavior of the individuals.

Since V (s) is now endogenous, the critical match-quality adopted by the agents when making partnership formation/dissolution decisions, $\boldsymbol{Q}$, is best viewed as a function of the matching probability Á. To highlight this we can introduce the notation $\not(A)$. Clearly, the larger is Á, the easier it is to ..nd new potential partners. This implies that singlehood becomes more attractive: why stay with a partner when the relationship has turned sour if it is easy to ..nd a new partner? Equally, it makes sense to be "picky" when meeting a new potential partner. Thus, as Á increases, $\not(A)$, should, if anything, increase. But a high $\not$ also implies an increased divorce risk, which should reduce the ..nancial cooperation that can be sustained; indeed the following result can be obtained:

Claim 4. The critical match-quality $\not(A)$ increases in $A$ and, moreover, risk-sharing $\mathbb{B}(\mu)$ decreases in Á for all $\mu>\beta$ 
Proof. See the A ppendix.

Note that Claim 4 indicates a key strategic complementarity: the larger is the fraction of the individuals who are single, the more attractive it is for each individual to join the pool of single individuals.

\section{Flow Equilibrium}

The steady state is characterized łow equilibrium. Moreover, the fraction of single individuals naturally depends positively on the critical match-quality $\mathbb{A}$. To see this, note that $S$ has the alternative interpretation as the fraction of țotal, time that an individual spends as single if the

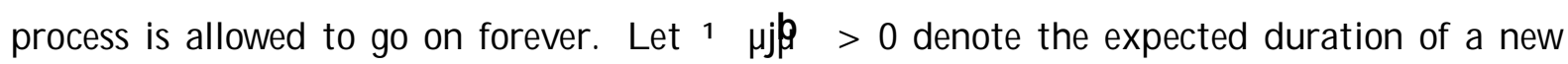
marriage with initial quality $\mu$ The expected time that a single individual, is away from the pool of singles upon meeting a potential partner is then $P_{\mu>\beta^{\prime}} f(\mu)^{1} \mu j \mid$, which naturally decreases in $\not$ (both since fewer meetings will result marriages, and since the expected duration of every new marriage will be shorter). Using that $1=A$ is the expected time until a potential partner is located the steady state fraction of single individuals must then satisfy:

$$
S=\frac{1 \neq A(S)}{1=A(S)+{ }_{\mu>q^{f}(\mu)^{1} \quad \mu j \beta}^{P}}:
$$

Equation (8) implicitly and uniquely de..nes $S$ as an increasing function of $\boldsymbol{Q}$, henceforth denoted s $\mathrm{p}$.

Lemma 5. The steady state fraction of single individuals in the economy, $S$, is increasing in the critical match-quality, $\mathrm{k}$

\section{Steady States}

A steady state equilibrium is characterized by two conditions: ‡ow equilibrium and individual rationality. Flow equilibrium was characterized just above, where it was found that the steady state fraction of single individuals, S, varied positively with the critical match-quality, Q Individual rationality requires that $\not$ is privately optimal given the matching-rate $A$, which in turn depends on S. A steady-state equilibrium can thus, be characterized as a ..xed-point for the mapping obtained by taking the composition of $S \mathcal{R}, \boldsymbol{A}(\hat{A})$ and $A(S)$; noting that all three components are non-decreasing (see Lemma 5 and Claim 4) it follows that the composite

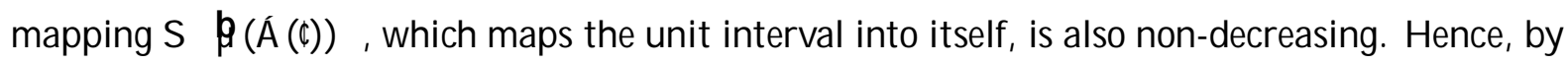


Tarski's ..xed-point theorem, an equilibrium exists. Furthermore, given that there is suc cient "spread" in match-qualities, any equilibrium will naturally be "interior". ${ }^{9}$

\section{Equilibrium Features}

This section ..rst looks at how the provision of formal insurance axects family-formation and cooperation in the general equilibrium setting. Then qualitative dixerences of multiple equilibria are investigated. Finally, the welfare properties of decentralized steady state equilibria are considered.

\section{General Equilibrium Exects of Formal Insurance}

The possibility of multiple equilibria oxers a potential explanation for why countries with similar levels of social expenditures can have quite dixerent family formation and dissolution patterns (as well as dixerent attitudes to the role of the family in providing ..nancial security). Moreover it allows this observation to be fully consistent with the claim that publicly provided insurance axects partnership formation and dissolution decisions, as well as the role of the family in providing ...nancial security, in a monotonic fashion.

To demonstrate this, publicly provided insurance is now introduced into the general equilibrium model. Consider again the case with only two income levels, $y^{1}$ and $y^{2}$; net incomes given by (4) and $i$ represents the generosity of public insurance. As usual with multiple equilibria, it is of interest to look at the "extremal equilibria". Thus let $S_{L}$ and $S_{H}$ denote the lowest- and the highest steady state fraction of single individuals respectively. To emphasize the impact of formal insurance, let $i$ be an argument for the two bounds, i.e. $S_{i}(i), i=L ; H$.

In Section IV is was noted that $q$ was increasing in $i$ when no remarriage was possible; the underlying reason was that formal insurance is more valuable to single individuals than to individuals who have access to informal risk-sharing. The same exect is at work in the general equilibrium context implying that $\not$ still tends to be increasing in $i$; although a general proof is not available, simple suф cient conditions can be obtained. Consider e.g. the following "memoryless stochastic process" which allows the match-quality to be a continuous variable, $f=\stackrel{f}{\mu} ; \bar{\mu}^{\alpha}$. Given any current match-quality $\mu$, the probability that a shock occurs, which

\footnotetext{
${ }^{9}$ If the best match-quality, $\mu_{N}$, is positive such a match will never be rejected. Moreover, if the worst match-
} quality, $\mu_{0}$, is so bad that an individual would rather be single forever, there will always be some single individuals. 
changes next period's match-quality, is, $2(0 ; 1)$ (conversely, with probability $1 \mathrm{i}$, the matchquality remains $\mu$ ). If a shock occurs the new match-quality is drawn from some distribution $F$, the density of which is strictly positive on $f$. Similarly, all initial match-qualities are also drawn from F . ${ }^{10}$ For this process - which will be used more extensively below - it can be shown that a suф cient (but not necessary) condition for $\not$ to be increasing in $i$ is that, $A^{11}$ The condition , Á implies that match-qualities are not too stable.

Returning to the main model, suppose then that $\not$ increases in $i$, i.e. that the direct exect is to make singlehood more attractive. Due to the strategic complementarity in the individuals' decisions to join the singles-pool, the direct exect carries over to the general equilibrium setting. The set of equilibria thus moves monotonically "upwards" as illustrated by Fig 2. The direct exect of the increased public insurance is to (weakly) increase $\mathrm{A}(\hat{A})$ for every Ás; a steady states exists wherever $\mathbb{R}(\dot{A}(S))$ intersects the $\neq$ ow-equilibrium condition $S=S R$ (which is unaxected by $i)$. Stated in precise terms:

CI a im 6 . Suppose that $M=2$ and that $\not$ increases in $i$; then $S_{L}(i)$ and $S_{H}(i)$ both increase in $i$.

Proof. See the A ppendix.

FIG 2.

The model thus predicts that there is an underlying monotonic impact of an expansion of formal insurance of family formation and breakup behavior in the sense that the set of equilibria moves towards people spending more time as single.

Letting $3 / 4$ denote the rate at which single individuals marry, $3 / 4=A ́(S) \quad 1$ i $F \quad \not A$, and using ${ }^{3}$ to denote the average rate at which married individuals divorce, $¥$ ow equilibrium implies $\mathrm{S}={ }^{3}=\left(3 / 4+{ }^{3}\right)$. Hence an expansion of formal insurance will increase the relative divorce rate $3=3 / 4 \mathrm{M}$ ore can be said about the absolute divorce rate if more speci..c stochastic processes are assumed. Consider e.g. the "memoryless" stochastic process introduced above. For this process

\footnotetext{
${ }^{10} \mathrm{~F}$ is also the long-run distribution associated with the stochastic process.

${ }^{11}$ For this speci..c process, $\phi(\mu)^{\prime} \vee(\mu)$ i $\vee(s)$ satis..es

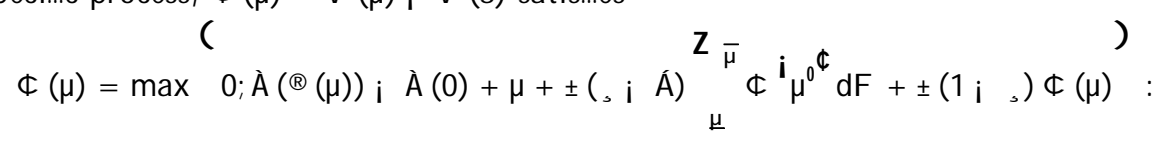

Using this a proof can be constructed along the lines of that of Claim 3.
} 
the average divorce rate ${ }^{3}$ is equal to,$F^{3} \not A$. Hence, for this speci..c process, ${ }^{3}$ increases as long as $\$$ increases.

The impact of insurance on the marriage rate $3 / 4$ is more ambiguous; on the one hand, if insurance leads to an increase in $\mathrm{R}$, this tends to decrease $3 / 4$ But on the other hand, since $S$ increases, so does the matching rate Á, generating an opposing exect on the marriage rate.

Turning to ..nancial cooperation, recall that risk-sharing is decreasing in the matching rate Á; then since insurance leads to an increase in $S$, and hence in Á, formal insurance leads to a reduction in cooperation in the sense that $®(\mu)$ decreases; in other words, the model exhibits crowding out also in the general equilibrium setting.

\section{Qualitative Dixerences of Multiple Equilibria}

The logic of the comparative static exercise carries over to a comparison of multiple equilibria. Thus consider an economy with at least two steady state equilibria; to avoid new notation consider the extremal equilibria, $L$ and $H$, where $S_{L}<S_{H}$. Since $S_{i}={ }^{3}{ }_{i}=\left({ }^{3} i+3 / 4\right), i=L ; H$ it follows that the relative aggregate divorce rate is higher in equilibrium $\mathrm{H}$ than in equilibrium $\mathrm{L}$, i.e. ${ }^{3} \mathrm{H}=3 / \mathrm{H}_{1}>{ }_{\mathrm{L}} 3 / \mathrm{E}$. M oreover, for the "memoryless" stochastic process the absolute divorce rate is higher in equilibrium $\mathrm{H}$ than in equilibrium $\mathrm{L},{ }^{3} \mathrm{H}>{ }^{3} \mathrm{~L} \cdot{ }^{12}$

Since, people spend more time as single (and generally marriages have shorter expected duration and divorce rates are higher) in equilibrium $\mathrm{H}$ than in equilibrium $\mathrm{L}$ it is natural to think of the former as a "high turnover" equilibrium and the latter as "low turnover" equilibrium. From the fact that the matching rate $A$ is higher in the high turnover equilibrium than in the low turnover equilibrium, it then also follows that, for any given current match-quality, $\mu$ a married couple cooperates less in the form of risk-sharing in the high turnover equilibrium than in the low turnover equilibrium.

The model thus captures the idea that two fundamentally similar economies can sustain dixerent equilibria where the people in one economy appear to be more "committed" to partnerships and cooperate more ..nancially than the people in the other economy. Such dixerences can be expected to be rełected in measured attitudes towards the role of the family. In other words, the role of social norms may be to act as a coordination device under multiple equilibria.

\footnotetext{
${ }^{12} \mathrm{~T}$ his follows since $\mathrm{S}$ is monotonically related to $\boldsymbol{Q}$ (Lemma 5$)$, and, for this speci..c process, ${ }^{3}=, F \quad Q$. Hence $S_{L}<S_{H}$ implies ${ }^{3} L{ }^{3} H$.
} 


\section{Welfare A spects}

In this short section I sketch two potentially important welfare implications of reciprocity-based cooperation. First, it is noted that while a standard search-externality would imply that there are too few single individuals in equilibrium, this conclusion can be overturned when expanding the pool of single individuals reduces the scope for cooperation by currently married couples. Second, it is noted that the presence of reciprocity-based cooperation may have implications for the desirability of variability in match-qualities.

A matched couple views their match as having an option value; this value determines the critical match-quality $\beta$ adopted in a decentralized steady state. Consider e.g. the memoryless stochastic process described above. Each individual treats the matching rate Á as given. A couple then stays together as long as the, value of doing so exceeds the value of breaking up, implying that $\mathrm{Q}$ is characterized by $\mathrm{V} \boldsymbol{Q}=\mathrm{V}(\mathrm{s})$. Manipulating this characterization, and using $r=(1 \mathrm{i} \#= \pm$ to denote the implicit "interest rate" corresponding to \pm yields the following more illuminating expression for $\boldsymbol{k}$,

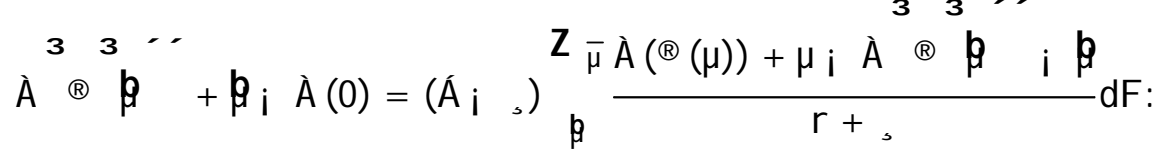

Note ..rst that the integral on the right hand side is positive since the current utility (when married) is increasing in $\mu$ The left hand side is the dixerence between then current utility from marriage at the critical match-quality 9 and the current utility from singlehood. This dixerence is then positive if and only if $A ́$ > , in other words, if joining the singles-pool is a faster way to obtaining a new match-quality than remaining married, then an individual is willing to forego current utility in order to take that chance.

If risk-sharing could be perfectly enforced, complete risk-sharing, $\mathbb{m}_{\mathrm{mk}}=1=2$, would always obtain. In that case the characterization of the socially ed cient cut-ox match-quality would be identical to Equation (9), except with ${ }^{i} \dot{A}+S A^{0} i,{ }^{\$}$ replacing $\left(\dot{A}_{i}\right.$, ), implying a higher cut-oæ

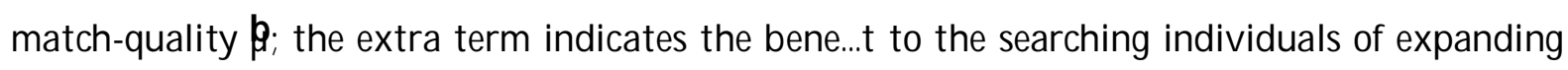
the pool of singletons (a standard search-externality - see e.g. Diamond, 1982). However, when risk-sharing cannot be legally enforced, the exect of expanding the pool of single individuals is to increase the matching rate Á which reduces the sustainable risk-sharing by currently married couples. In other words, the exect of expanding the pool of single individuals is also to make divorce privately more attractive, which, when cooperation is sustained by reciprocity, reduces 
risk-sharing by currently married couples. ${ }^{13}$

Hence, contrary to the case where any amount of cooperation can be sustained, in this case a steady state equilibrium may have (locally) too few married individuals. Equally, if there are multiple equilibria these cannot be unambiguously welfare-ranked: whether a "high turnover" equilibrium (with a high average match-quality among married individuals and low levels of risk-sharing) or a "low turnover" equilibrium (with a lower average match-quality but higher levels of risk-sharing) is better cannot be determined on an a priori basis.

A second welfare implication of reciprocity-based cooperation concerns the variability in match-qualities. Suppose that risk-sharing could be enforced; in that case the value function $V(\mu)$ would be naturally convex. The convexity arises since the individuals have the option of leaving bad matches and instead joining the marriage market. ${ }^{14}$ In that case, an increase in the spread of the long-run distribution, $F$, of match-qualities implied by the stochastic process will generally be good for welfare. The intuition is simple: increasing the probability of good states and bad states, while keeping the average constant, will be good for welfare since the good states will be enjoyed while the bad states can be rejected.

In contrast, when risk-sharing is based on expected reciprocity, an increase in match-quality not only has a direct value, but also enhances risk-sharing. However, the second bene.t to increased match-quality eventually diminishes since the value of insurance diminishes (due to $u$ being concave) and, also, since at good-enough match-qualities, complete risk-sharing may be sustainable.

A s a consequence, the value function $V(\mu)$ generally fails to be globally convex (but, rather, tends to have an infection point). As a consequence, a mean-preserving spread in the long-run distribution of match-qualities, $F$, need not be welfare improving. Intuitively, if probability mass is (marginally) shifted from middle-range values the impact on the direct bene..t is negligible, but the loss of utility due to reduced risk-sharing from the downward shifting of mass may not be matched by a corresponding increase in utility from increased risk-sharing associated with the upward shift of mass. Hence, with reciprocity-based cooperation, it may be bene..cial to

\footnotetext{
${ }^{13} \mathrm{~N}$ ote that even when risk-sharing is enforced, a married couple would become more prone to divorce when an additional individual joins the pool of singletons: this is simply to the strategic complementarity and would not constitute an externality. The dixerence here is that the utility of a married couple is negatively axected while remaining married.

${ }^{14}$ Consider e.g. the "memoryless" stochastic process described above; with enforced complete risk-sharing, $V(\mu)$ would be linearly increasing in $\mu$ above $\mid$ and equal to $V(s)$ at all $\mu \cdot R$, thus making $V(\mu)$ globally convex.
} 
welfare if match-qualities are less variable (that is, if there are less "booms and busts" in love) since this may promote valuable cooperation between partners.

\section{Extensions}

Duration Dependence and Learning A restrictive feature of the above framework is that partnership duration has no role to play, neither for partnership dissolution behavior nor for cooperation. Duration exects on the divorcehazard has, however, been observed empirically (Weiss and Willis, 1997). Incorporating duration exects would require a dixerent modeling strategy; an interesting alternative would be to abandon the Markov assumption and instead assume that, for each couple, there exists an underlying match-quality which is ..xed, but which is only revealed over time (in the spirit of J ovanovic (1979)). A couple that is observed to have stayed together for a long time is then likely to strongly believe that their match-quality is good. Since in such a generalization, risk-sharing would be positively related to the couple's current beliefs that their match is good, cooperation would tend to be positively related to duration.

Relation-Speci..c Investments Empirical evidence suggests that children and joint property stabilize marriages, causing the individual divorce hazard to drop over time (see Weiss and Willis, 1997). The above model abstracted from relation-speci..c investments in order to keep the analysis manageable. Incorporating relation-speci..c investments into stochastic models of marriage and divorce poses a great challenge; the incentives for investments hinges in an interesting way on the degree of irreversibility of such investments, and on the assumed stochastic structure (see Drewianka, 2000). E.g. in the current framework, it is conceivable that irreversible relation-speci..c investments (e.g. having a child, building a common network of friends etc.) may increase divorce costs. However, in the current framework "love never lasts forever" which limits the incentives for such investments.

One approach that is feasible within the current framework is to treat investments as occurring exogenously. ${ }^{15}$ If a stock investments increases the cost of divorce, it also axects divorce behavior and ..nancial cooperation. So, for example, the presence of children can be expected to be associated with more ...nancial cooperation. Similarly, investments, in so far as they are

\footnotetext{
${ }^{15} \mathrm{~A}$ simple formulation would be to include a bene..t ${ }^{\circ}$ from marriage (in addition to the match-quality $\mu$ ) which increases in duration ${ }^{\circ}(t+1)>{ }^{\circ}(t)$. This would make the value function duration dependent, but the analysis and the results would still go through.
} 
unobserved, may contribute to duration dependence in divorce behavior and ..nancial cooperation.

Persistent Income Shocks Allowing persistent income shocks could potentially lead to a number of interesting insights. When risk-sharing relies on reciprocity, an individual's willingness to make transfers to his/ her partner hinges on an expectation that the favour may be reciprocated sometime in the future. However, if income shocks are strongly persistent, then the time until any favour can be expected to be reciprocated will be long. Hence it is possible that e.g. labour market institutions will have implications for the sustainability of ..nancial cooperation.

However, allowing persistent income shocks would also complicate the analysis. E.g. when meeting in the marriage market each single individual would be characterized by an individualspeci..c expected stream of future incomes. Thus it would be necessary to consider bargaining between newly matched individuals.

\section{An Tentative Empirical Investigation}

The above analysis suggests that ..nancial cooperation between partners may be axected both by marriage market conditions and welfare spending. Testing this requires comparing outcomes across economies. While any such investigation must necessarily be treated with caution, this section presents a tentative analysis. The need to use cross-country data unfortunately rules out using micro-level data on individual consumption levels (as is typically used in the literature on intra-household allocations ${ }^{16}$ ). Instead I rely on a self-reported measure of cooperation obtained from the International Social Survey Programme (ISSP) 1994 survey on "Family and Changing Gender Roles". C ouples were asked how they organize their incomes, in particular whether they "pool their incomes". One potential problem is that the interpretation of "income pooling" is not unequivocal, and may not be equivalent to "risk-pooling", especially if it reł ects the outcome of a joint household decision making process involving specialization. W hat is of key importance for our purposes is that the reported measure captures an element of reciprocity-based cooperation. However, in the hope to capture risk-pooling rather than specialization, I focus on individuals who are full-time employed, and whose partners are also full-time employed. ${ }^{17}$

\footnotetext{
${ }^{16}$ See e.g. B rowning and Chiappori (1996) and the references therein.

${ }^{17}$ Including part-time employed workers did not signi..cantly axect the results.
} 
I use two binary dependent variables: ..rst whether the respondent has a "partner", and second, if so, whether "incomes are pooled". Both decisions depend on unobserved stochastic factors, e.g. match-quality, which can be expected to be correlated. Hence I use a bivariate probit model with sample selection which is estimated using the maximum likelihood method. Let $z^{\mathfrak{\alpha}}=-q_{x}+$ " be a latent variable. The respondent "has a partner" $(z=1)$ if $z^{\mathfrak{\alpha}}>0$ and is "single" $(z=0)$ otherwise. For those individuals who have partners, let $q^{\alpha}=\circ q_{w}+$ ' be a second latent variable such that income pooling with the partner is "complete" $(q=1)$ if $q^{\text {a }}>0$ and otherwise is "incomplete" ( $q=0)$ (see below). ("; ') has a bivariate normal distribution with zero means, unit variances and correlation $1 / 2$ The two sets of regressors, $x$ and $w$, may overlap but need not be identical.

\section{The Data}

The ISSP 1994 survey was conducted in 22 countries; however, I restrict my attention to OECD countries; I also restrict the sample to individuals aged 20-65 who are full-time employed, and whose partners, if any, are al so full-time employed. The ..nal sample consists of 7,779 individuals from 16 countries: A ustralia, A ustria, Canada, Czech Republic, Germany, Hungary, Ireland, Italy, J apan, Netherlands, New Zealand, Norway, Poland, Sweden, UK, and the US. ${ }^{18}$

I include a number of market-level variables. To capture the exect of welfare policy, I use social transfers as per cent of GDP. I include each country's divorce rate (divorces per 1000 population). As measures of labour market institutions I use the female labour force participation rate and an employment protection legislation index calculated by the OECD which can range (continuously) from 0 to 6 with higher values representing stricter regulation. ${ }^{19}$

At the individual level age, age squared, gender (dummy for "male") were included in both sets of regressors. For education, categories were used; the base category is "some secondary education" and dummies were included for "primary education or less" and "some university education". In the income-pooling equation I use information on household earnings (log of net annual earnings in 1994 US Dollars). Since children, as a relation-speci..c investment, may

\footnotetext{
${ }^{18}$ Spain had to be eliminated due to lack of information on education.

${ }^{19}$ Social transfers were obtained from the OECD Social Expenditure Database 1980-1997 (See fn. 1). Supplementary information was obtained from the IMF G overnment F inance Yearbooks. Divorce rates are from the UN 1997 Demographics Yearbook. Female labour force participation rates were obtained from the ILO Yearbooks of Labour Statistics. The employment protection index is from OECD E mployments Outlook, J une 1999, Table 2.5, O verall strictness, version 1.
} 
stabilize marriages I control for household size. I include dummies for prior divorce: though the theory does not predict any direct impact of prior divorce on ..nancial cooperation, it is likely to be negatively related to the (unobserved) duration of the current relationship and can therefore be expected to be negatively associated with cooperation. Finally, dummies were included for "regular attendance to religious services" and self-employment.

The ..rst dependent variable is a dummy which is unity if the respondent has a "partner" (spouse or steady life-partner). For those individuals with partners there is a second dependent variable constructed from the following question:

How do you and your spouse/ partner organize the income that one or both of you receive?

The available answers were (i) "I manage all the money and give my partner his/ her share", (ii) "My partner manages all the money and gives me my share", (iii) "We pool all the money and each take what we need", (iv) "We pool some of the money and keep the rest separate", (v) "We each keep our own money separate". The most frequent answer was (iii); only about 12 percent of the answers fell in category (i) and (ii). I interpret (i) through (iii) as full ..nancial cooperation or "full income pooling", (y=1) while (iv) and (v) is interpreted as "incomplete income pooling" $(y=0)$.

\section{Results}

As a preliminary step I estimated the model using only the explanatory variables measured at the individual level together with a set of country-dummies. ${ }^{20}$ This revealed signi..cant country exects. E.g. people in the Nordic countries in particular were less likely to pool their incomes conditional on having a partner. I then proceeded by replacing the country-dummies with the aforementioned market-level variables. This produced no qualitative exects on the coec cients for the individually measured variables.

Column 2 of Table 1 shows the result for the "partner-equation". ${ }^{21}$ The "marginal exects"

\footnotetext{
${ }^{20} \mathrm{~T}$ he results are available on request from the author.

${ }^{21}$ O ne must however keep in mind the limitations; since the key variables are only measured at the country-level the "exective number of observations" is obviously low. Also, if the individuals in the same country are axected by some common component not accounted for their error terms will be correlated; the exects of the country-level variables may then be measured less precisely than their t-ratios suggest.
} 
in this case are calculated as traditional probit marginal exects:

$$
\frac{@ \operatorname{Pr}(z=1 j x)}{@ x}=A^{i-q^{\phi}-}
$$

where $A(\Phi$ is the pdf for the standard univariate normal distribution.

A ge is naturally the most important factor explaining whether or not an individual has a partner. In line with the literature, education also matters. Relative to primary education, having secondary education increases the probability of having a partner. Further education on the other hand reduces the probability of having a partner, possibly because highly educated individuals tend to marry late. A prior divorce naturally negatively axects the probability of currently having a partner. The female participation rate comes out signi..cant and may be picking up cultural factors when country-dummies are not employed. ${ }^{22}$

Turning to the aggregate divorce rate and to social transfers, both have negative signs, but only the aggregate divorce rate is signi..cant. The negative exect of the aggregate divorce rate suggests the presence of a "social multiplier" (Becker and Murphy, 2000) arising from strategic complementarities in marriage market behavior. Checking the predictions from the model did not reveal any strong geographical patterns of over- and under-predictions.

More interesting for our purposes is the "income-pooling equation", the results for which are presented in column 1 of Table 1. The marginal exects reported in this case are the direct exects of the regressors in $\mathrm{w}$ on the conditional probability of pooling income,

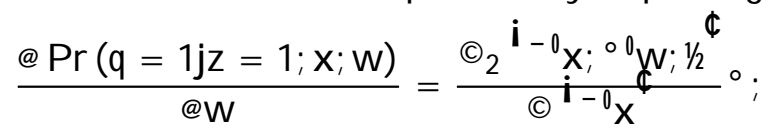

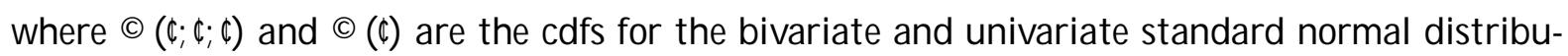
tion, respectively.

A ge axects the probability of income pooling positively over most of the range; this is natural if there is learning about an underlying match-quality and/or unobserved relationspeci..c investments since "age" picks up the exect of (unobserved) duration. Higher education negatively axects income-pooling; this may be to due to short duration. However, it may also be that education acts to stabilize the income streams reducing the need for risk-sharing. Income negatively axects income pooling. ${ }^{23}$ Household size is positively associated with income pooling which is consistent with the stabilizing exect of relation-speci..c investments (and that kids appear when the partners perceive that their match-quality is good).

\footnotetext{
${ }^{22}$ Its measured exect may also rełect the focus on full-time employed couples.

${ }^{23}$ See Coate and Ravallion (1993) for comparative statics on reciprocity-based income-sharing.
} 
Prior divorce, both for the respondent as well as the respondent's partners, strongly reduces the probability of income pooling. Though prior divorce plays no direct role in the theory above, it may play a role if there is learning and/ or relation-speci..c investments since prior divorce signals short duration of the current relationship. The labour market variables - the female participation rate and employment protection - have no signi..cant exects on income-pooling.

Turning to the main variables of interest, social transfers has a signi..cant negative exect on income pooling, suggesting that public insurance indeed crowd out informal income-sharing within partnerships. The aggregate divorce rate also negatively exects income pooling: a couple living in an economy where breakups are more frequent would thus appear to be less likely to cooperate ..nancially than an otherwise identical couple. Finally the estimated correlation coef..cient $1 / 2$ is positive which is consistent with both decision being driven by a common unobserved match-quality. ${ }^{24}$

In conclusion the results - though best cautiously interpreted - seem consistent with the theory. Social spending appears to axect both family formation decisions, as well as ..nancial cooperation by partners. In addition, the structure of the marriage market appears to axect ...nancial cooperation with a high turnover reducing income pooling.

\section{Conclusions}

It is sometimes argued that welfare state arrangements break up families, partly because they take on some of the functions otherwise performed by the family. This paper constructs a stylized model of marriage and divorce in which partners can cooperate ..nancially by sharing earnings-risk. Risk-sharing between partners is supported by expected reciprocity. Any policy change that increases the relative attractiveness of divorce will not only directly increase the individuals' proneness to choose singlehood, but will also reduce the level of cooperation between partners which in turn further reduces the relative attractiveness of marriage and so on. Hence the analysis suggests that the nature of reciprocity-based cooperation between partners implies that changes in welfare policies can have strong exects on both family formation and dissolution patterns, as well as on cooperation. The model thus highlights how reciprocity-based ..nancial cooperation between partners can have important implications for policy-design.

The model further reconciles the observation that there is a fairly low correlation in a simple

\footnotetext{
${ }^{24} \mathrm{~A}$ Wald test of the hypothesis that the equations are independent is rejected at the 8 percent level.
} 
cross-country comparison of welfare spending and e.g. divorce rates with the claim that publicly provided insurance monotonically axects family formation and dissolution decisions. The mechanism underlying the last result is a standard complementarity in search in the marriage market. As a consequence an economy can sustain multiple steady state equilibria dixering in the rate of turnover in the marriage market and in the role of partners in providing ..nancial security.

A decentralized steady state equilibrium generally fails to be locally ined cient, and it is argued that the presence of reciprocity-based cooperation implies that the direction of ined ciency is ambiguous: an equilibrium may have too few married individuals.

\section{A ppendix}

Proof of Claim 1. Let $B(f)$ denote the space of bounded real-valued functions on $f$, and endow this space with the sup norm. Blackwell (1965) provides the following suф cient condition for $T: B(f)$ ! $B(f)$ to be a contraction mapping (with modulus ${ }^{-}$):

1. (monotonicity) $f ; g 2 B(f)$ and $f(\mu), g(\mu)$ for all $\mu 2 f$ implies $\left(T_{f}\right)(\mu),\left(T_{g}\right)(\mu)$ for all $\mu 2 f$, and

2. (discounting) there exists some ${ }^{-} 2(0 ; 1)$ such that $\left(T_{f+a}\right)(\mu) \cdot\left(T_{f}\right)(\mu)+{ }^{-}$a for all $f 2 B(f) ; \mu 2 f$ and $a, 0$.

De..ne a mapping $T: B(f) ! B(f)$ in the following way: for each $f 2 B(f)$ let

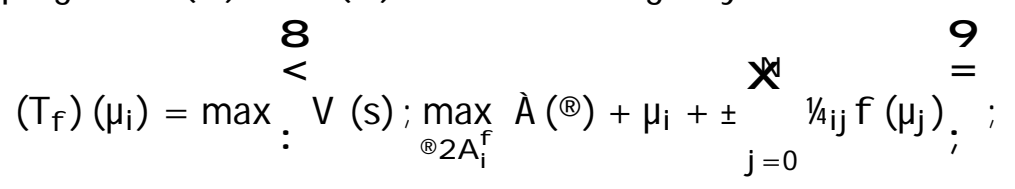

where ${ }^{\circledR} 2 A_{i}^{f}$ if and only if ${ }^{2} 2 A$ and, for all $m>k$ such that $\AA_{m k}>0$,

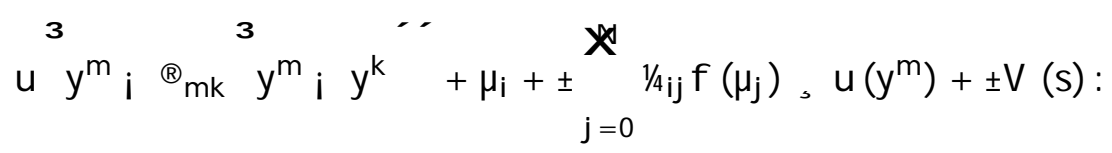

Lemma A.1. T is a contraction mapping.

Proof. The proof uses Blackwell's suф ciency conditions. Consider ..rst "monotonicity". From Equation (A 2) it follows that $f(\mu), g(\mu)$ for all $\mu 2 f$ implies $A_{i}^{g} \mu A_{i}^{f}$ for all $i$; "monotonicity" then follows immediately follows from Equation (A1). 
Consider then "discounting". Let $i \mathrm{i}(\mathrm{a})$ " $\max _{\circledast 2 \mathrm{~A}_{i}^{f+a}} \grave{A}(\AA)+ \pm a$ and note that $\left(\mathrm{T}_{f+a}\right)\left(\mu_{i}\right)=$ $\max f V(s) ; i j(a)+K_{i}$ g where $K_{i}$ does not depend on $a$. If $i_{i}(a)$ then always grows at a rate less than unity, "discounting" holds. Totally dixerentiating (1) and substituting for $\mathrm{d} \mathbb{\mathrm { m }}_{\mathrm{mk}}=\mathrm{da}$ using (A 2) yields

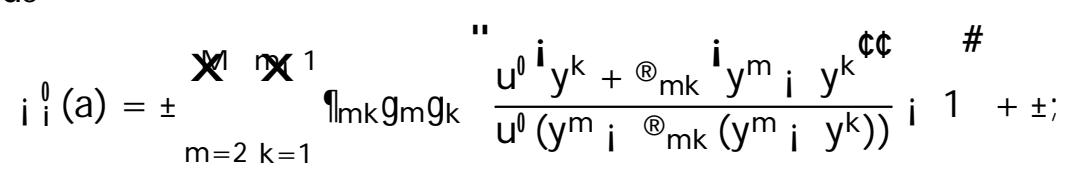

where $9_{m k}=1$ if the $\mathrm{mk}^{\prime}$ th incentive constraint is relaxed by the increase in a and else is zero. Thus, since $\AA_{m k} 2[0 ; 1=2]$ and $y^{m}>y^{k}$,

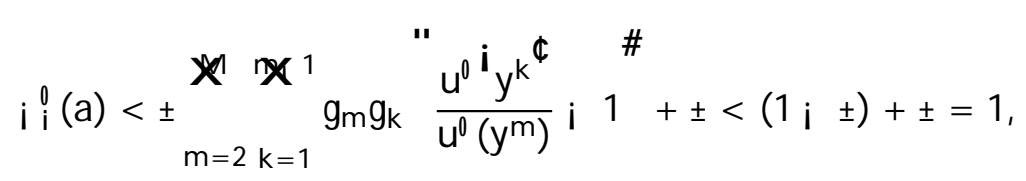

where the second inequality follows from A ssumption 2. \#

Since $T$ is a contraction mapping it has a unique ..xed point $f$ $2 B(f)$ and furthermore, $T_{h}^{n}$ ! $f^{\text {x as } n ! ~} 1$ for any $h 2$ B ( $f$ ) ("the method of successive approximations"). From (2) and (3) $T_{V}=V$; thus $V$ exists and is unique. Then apply the method of successive approximations: de.ne $V_{0}(\mu)=\mu$ for all $\mu 2 \mathrm{f}$. For $n, 1, V_{n}$ is recursively de..ned: $V_{n}=T_{V_{n i}}$ (implying that $\left.V_{n}=T_{V_{0}}^{n}\right)$. Since $f$ is ordered increasingly $V_{0}\left(\mu_{j}\right)$ increases in $j$. A ssume then that $V_{n_{i} 1}\left(\mu_{j}\right)$ also increases in $j$. Using stochastic dominance (A ssumption 1$),{ }_{j=0}^{N}{ }^{1 / 4 j} V_{n_{i} 1}\left(\mu_{j}\right)$ then increases in $i$, whereby $i>j$ implies $A_{j}^{V_{n_{i} 1}} \mu A_{i}^{V_{n_{i} 1}}$. Consequently

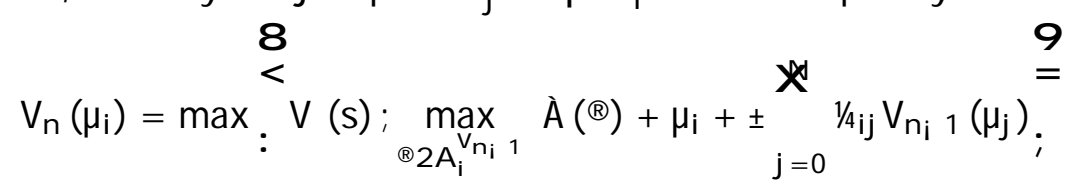

increases in $\mathrm{i}$. By induction on $n, V_{n}\left(\mu_{i}\right)$ increases in i for all $n$, whereby $V\left(\mu_{i}\right)=\lim _{n} ! 1 V_{n}\left(\mu_{i}\right)$ also increases in $i$. Since $f$ is ordered increasingly, this is equivalent to $V(\phi$ being increasing in $\mu$

Proof of Claim 2. Since the incentive constraints are independent of each other (see Equation (3)) $A_{i}$ can be expressed as follows: $A_{i}=f_{m>k}\left[0\right.$; $\left.\mathbb{Q}_{m k}\right]$ where each $\mathbb{R}_{m k}$ is an upper bound

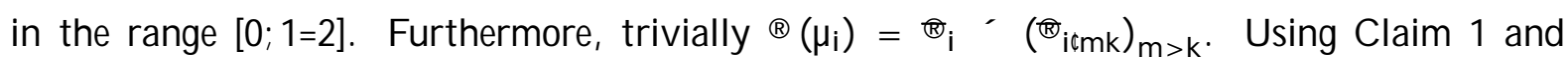
stochastic dominance (Assumption 1 ), $\mathrm{i}>\mathrm{j}$ implies $A_{j} \mu A_{i}$ whereby $\mathbb{R}$.

Proof of Claim 3. The Claim follows if $\phi(\mu)^{\prime} V(\mu) ; V(s)$ decreases in $i$ for all $\mu 2 f$. The argument is by induction. Consider an n-period approximation to original problem: Suppose the couple must divorce after $\mathrm{n}$ periods, but can divorce at any time before that. (T he reader might argue that no risk-sharing can be sustained if the horizon is known to be ..nite. However, that 
relies on a subgame perfection argument that does not invalidate the approximation.) Let $V_{n}(\mu)$ denote the value of being in state $\mu$ with a maximum of $n$ periods remaining; then as the horizon $\mathrm{n}$ goes to in..nity it's impact will vanish. Since no remarriage is possible $V(s)=\grave{A}(0)=(1 ; \quad \#$.

When $n=0, V_{0}(\mu)=V(s)$ for all $\mu 2 f$, and $\phi_{0}(\mu)=V_{0}(\mu) ; V(s)$ trivially (weakly) decreases in $i$ for all $\mu 2 \mathrm{f}$. A ssume then that $\phi_{n_{i} 1}(\mu)$ decreases in $i$ for all $\mu 2 f$. For $n, 1$, $V_{n}(\emptyset$ satis..es the following recursive de..nition:

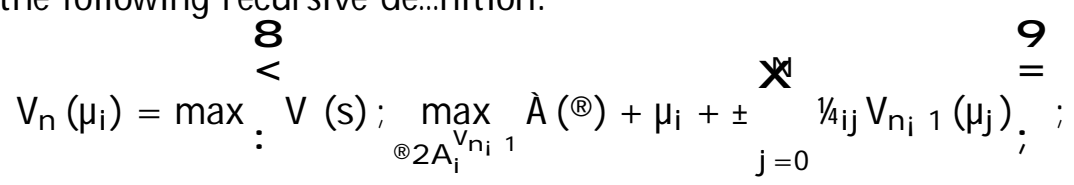

where ${ } 2 A_{i}^{V_{n_{i} 1}}$ if and only if ${ }^{2} 2 A$ and, for all $m>k$ such that $\mathbb{R}_{\mathrm{mk}}>0$,

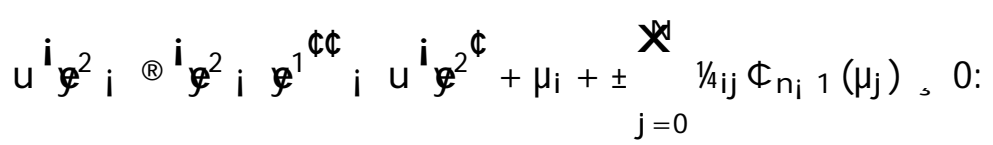

Using that $(1 ; \sharp V(s)=\grave{A}(0)$, it follows that

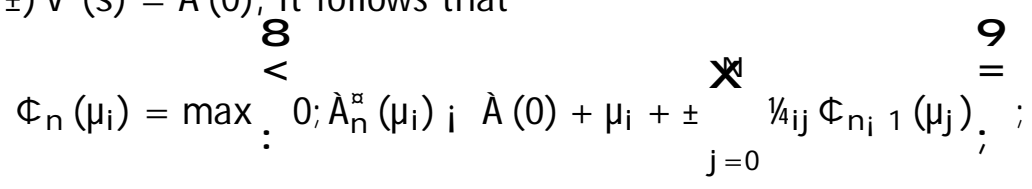

where $\grave{A}_{n}^{\alpha}\left(\mu_{i}\right)^{\prime} \max _{{ } 2 A_{i}^{n_{n_{i} 1}}} \grave{A}(\Theta)$. Thus if $\grave{A}_{n}^{\alpha}\left(\mu_{i}\right) ; \dot{A}(0)$ decreases in $i_{1} \phi_{n}\left(\mu_{i}\right)$ will also decrease in $i$. If complete risk-sharing is sustainable, $\grave{A}_{n}^{\alpha}\left(\mu_{i}\right)=\grave{A}(1=2)$; but $\grave{A}(1=2)$ i $\grave{A}(0)$ naturally decreases in $i$ since the additional formal insurance is more valuable when no risksharing is available. Suppose then that risk-sharing is incentive constrained implying that (A 4) holds with equality. An increase in $i$ decreases $\ell^{2}$ as well as $\phi_{n_{i}}\left(\mu_{j}\right)$ for every $j$; from (A 4) (using $\mathrm{u}^{\infty}<0$ ) the self-enforceability constraint is therefore tightened, forcing a reduction in the absolute transfer $\Theta^{i} \varphi^{2} i \varphi^{1^{\Phi}} . \dot{A}_{n}^{\alpha}\left(\mu_{i}\right) ; \dot{A}(0)$ then decreases in $i$ also due to the crowding out exect on private risk-sharing. By induction on $n, \phi_{n}(\mu)$ then decreases in $i$ for every $\mu 2 \mathrm{f}$ and $n$. Letting $n$ go to in..nity $\phi(\mu)=\lim _{n ! 1} \phi_{n}(\mu)$ also decreases in $i$ for each $\mu 2 \mathrm{f}$.

Proof of Claim 4. The proof uses that Á axects $\vee(\mu)$ only through $V(s)$. Thus start by treating $\mathrm{V}(\mathrm{s})$ as parametrically given and note that:

Lemma A .2. $\phi(\mu)^{\prime} \vee(\mu) ; V(s)$ and $\Theta(\mu)$ decreases in $V(s)$ for all $\mu 2 f$.

Proof. The proof uses the same n-period approximation as used in the proof of Claim 3. For $\mathrm{n}=0, V_{0}(\mu)=V(\mathrm{~s})$ for all $\mu 2 \mathrm{f}$ while for $\mathrm{n}, 0, V_{n}(\mu)$ is de..ned recursively as in (A3), where now $\AA_{2} A_{i}^{V_{n_{i} 1}}$ if and only if $\AA_{2} A$ and, for all $m>k$ such that $\AA_{m k}>0$,

$$
u y^{m} i \otimes_{m k}^{3} y^{m} i y^{k}+\mu_{i} i u\left(y^{m}\right)+ \pm_{j=0}^{N^{N}} 1 / x_{j j} \$_{n_{i} 1}\left(\mu_{j}\right), 0:
$$


$\$_{0}(\mu)=V_{0}(\mu)$ i $V(s)$ trivially (weakly) decreases in $V(s)$ for all $\mu$ Assume then that $\phi_{n_{i} 1}(\mu)$ decreases in $V(s)$ for all $\mu$ From (A 6) the set $A_{i}^{V_{n_{i} 1}}$ then decreases in $V(s)$. Note that

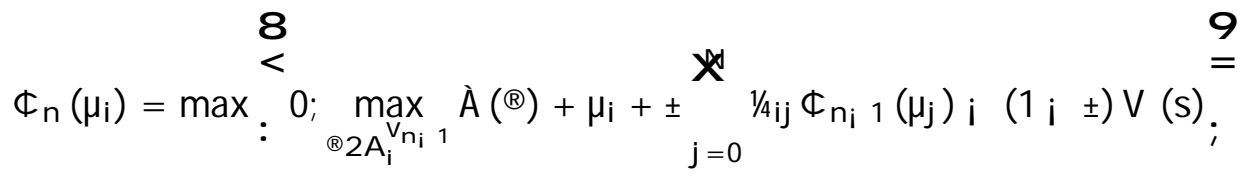

Hence $\phi_{n}\left(\mu_{i}\right)$ decreases in $V(s)$. Moreover, as noted in the proof of Claim 2, $A_{i}^{V_{n_{i}}{ }^{1}}$ can be expressed as the cross-product of $M(M ; 1) \Rightarrow 2$ intervals where the set of upper bounds is the optimal risk-sharing agreement. Then since $A_{i}^{V_{n_{i} 1}}$ decreases in $V(s)$ for all $i$ it follows that $\mathbb{R}_{\mathrm{h}}(\mu)$ decreases (component by component) in $\mathrm{V}(\mathrm{s})$ for all $\mu$ By induction on $\mathrm{n}$ it follows that $\phi_{n}(\mu)$ as well as $\mathbb{R}_{\mathrm{n}}(\mu)$ decreases in $\mathrm{V}(\mathrm{s})$ for all $\mathrm{n}$ and $\mu$ Letting $\mathrm{n}$ ! 1 the result follows. \# Lemma A.3. V(s) increases in Á.

Proof. Subtracting $V(\mathrm{~s})$ from both sides of (7) shows that:

$$
\frac{\left(1_{p} \quad \pm V(s) \text { i } \grave{A}(0)\right.}{ \pm \underset{j=0}{N} f\left(\mu_{j}\right) \phi\left(\mu_{j}\right)}=\dot{A}
$$

holds identically. Noting that I.h.s. increases in V (s) (by Lemma A.2) the result follows. \#

Combining Lemma A.3 and Lemma A.2 and noting that divorce is optimal whenever $\phi(\mu)=$ 0 , monotonicity of $\not$ and $\mathbb{B}(\mu)$ in Á follows.

Proof of Claim 6. Since $f$ is discrete and each component of the composite mapping $S \boldsymbol{R}(\dot{A}(\phi)$ are increasing, the composite mapping is an increasing step-function and is hence "continuous but for upward jumps". Furthermore, since Q increases in $i$ the composite mapping increases in $i$; then from Milgrom and Roberts (1994, Corollary 1 ) it follows that the lowest and the highest ..xed point, $S_{L}(i)$ and $S_{H}(i)$, both increase in $i$.

\section{References}

A iyagari, S. R., Greenwood, J . \& Guner, N. (2000), 'On the state of the union', J ournal of Political E conomy 108, 213-244.

Attanasio, O.\& Rios-Rull, J.-V. (2000), 'Consumption smoothing in island economies: Can public insurance reduce welfare?', European Economic Review 44, 1225-1258.

Becker, G. S. (1973), 'A theory of marriage: Part I', J ournal of Political E conomy 81, 813-846. 
Becker, G. S. (1991), A Treatise on the Family, 2'nd edn, Harvard University Press, Cambridge, Mass.

Becker, G. S., Landes, E. \& Michael, R. (1977), 'A n economic analysis of marital instability', J ournal of Political Economy 85, 1141-1187.

Becker, G. S. \& Murphy, K. (2000), Social Economics: Market Behavior in a Social Environment, B elknap Press of Harvard University Press, Cambridge, MA.

Berry-Cullen, J . \& Gruber, J . (2000), 'D oes unemployment insurance crowd out spousal labor supply?', J ournal of Labor Economics 18, 546-572.

Blackwell, D. (1965), 'Discounted dynamic programming', Annals of Mathematical Statistics 36, 226-235.

Browning, M . \& Chiappori, P. A. (1996), ' $E \$$ cient intra-household allocations: A general characterization and empirical tests', E conometrica 66, 1241-1278.

Bumpass, L. L. \& Sweet, J . A . (1989), 'National estimates of cohabitation', Demography 26, 615625.

B urdett, K . \& Coles, M . (1997), 'M arriage and class', Q uarterly J ournal of E conomics 112, 141168.

Burdett, K . \& Ermisch, J . (2001), 'M atching in the marriage market and non-marital childbearing'. Working Paper No 10/ 2001, Centre for Household, Income, Labour and Demographic E conomics (ChilD).

Burdett, K ., Imai, R . \& Wright, R. (1999), 'U nstable relationships'. University of E ssex, M imeo.

Chiappori, P. A . \& Weiss, Y . (2000), 'M arriage contracts and divorce: An equilibrium analysis'. University of Chicago, Mimeo.

Coate, S. \& Ravallion, M. (1993), 'Reciprocity without commitment: Characterization and performance of informal insurance arrangements', J ournal of Development E conomics 40, 124.

Diamond, P. A. (1982), 'A ggregate demand management in search equilibrium', J ournal of Political E conomy 90, 881-894. 
DiTella, R. \& M acCulloch, R. (1999), 'Informal family insurance and the design of the welfare state', E conomic J ournal. Forthcoming.

Drewianka, S. (2000), 'P roposed reforms of marital institutions'. U niversity of Chicago, M imeo.

Foster, A. D. \& Rosenzweig, M. R. (2000), 'Imperfect commitment, altruism and the family: Evidence from transfer behavior in low-income rural areas', Review of Economics and Statistics . Forthcoming.

Greenwood, J., Guner, N. \& Knowles, J. (2000a), 'A macroeconomic analysis of marriage, fertility, and the distribution of income'. University of Pennsylvania, Mimeo.

Greenwood, J., Guner, N. \& K nowles, J . (2000b), 'Women on welfare: A macroeconomic analysis', American Economic Review: Papers and Proceedings 90, 383-388.

Hess, G. D. (2001), 'M arriage and consumption insurance: What's love got to do with it?'. Oberlin College, M imeo.

J ovanovic, B. (1979), 'J ob-matching and the theory of turnover', J ournal of Political Economy 87, 972-990.

K imball, M. (1988), '"Farmers" cooperatives as behavior toward risk', A merican Economic Review 78, 224-232.

K ocherlakota, N. R. (1996), 'Implications of eф cient risk sharing without commitment', Review of Economic Studies 63, 595-609.

Ligon, E., Thomas, J. P. \& Worrall, T. (1997), 'Informal insurance arrangements in village economies'. Keele University, Department of Economics, Working Paper 97/ 08.

Ligon, E., Thomas, J . P. \& Worrall, T . (1998), 'M utual insurance, individual savings and limited commitment'. University of St Andrews, Mimeo.

L undberg, S. \& Pollak, R. A . (1994), 'N oncooperative bargaining models of marriage', A merican E conomic Review (Papers and Proceedings) 84, 132-137.

Lundberg, S. \& Pollak, R. A. (2001), 'E \ ciency in marriage'. NBER Working Paper No. W 8642. M ilgrom, P. \& Roberts, J . (1994), 'Comparing equilibria', American E conomic Review 84, 441459. 
M ortensen, D. T . (1988), 'M atching: F inding a partner for life or otherwise', A merican J ournal of Sociology 94, S215-S240.

Peters, E. (1986), 'Marriage and divorce: Informational constraints and private contracting', A merican Economic Review 74, 437-454.

Weiss, Y . (1997), The formation and dissolution of families: W hy marry? W ho marries whom? A nd what happens upon divorce?, in M. R. Rosenzweig \& O. Stark, eds, 'Handbook of Population and Family Economics', Elsevier Science B.V., A msterdam.

Weiss, Y . \& W illis, R . (1997), 'M atch quality, new information and marital dissolution', J ournal of Labor E conomics 15, S293-S329. 

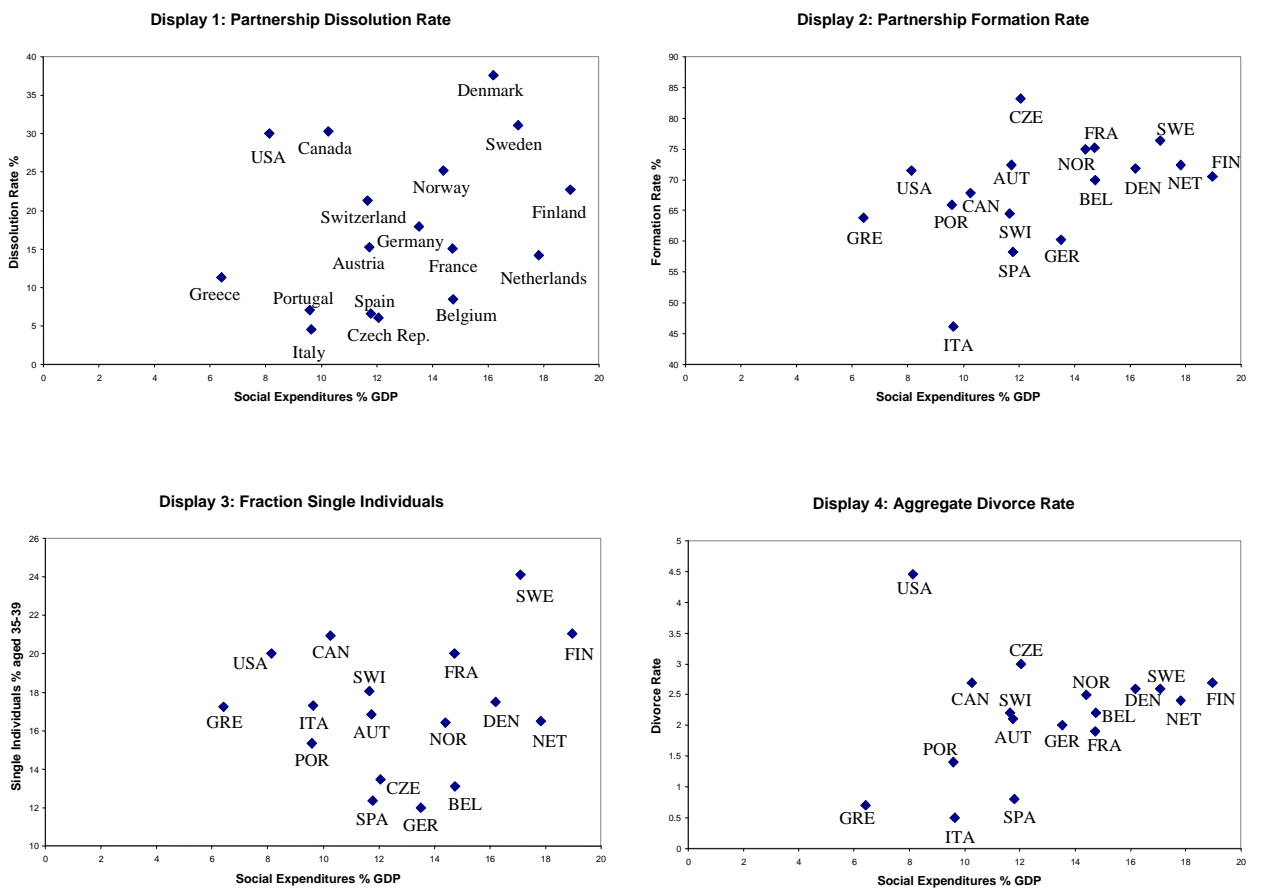

Figure 1: Social expenditures (percent of GDP in 1994), and measures of partnership formation and dissolution rates, partnership frequency, and aggretage divorce rate. 


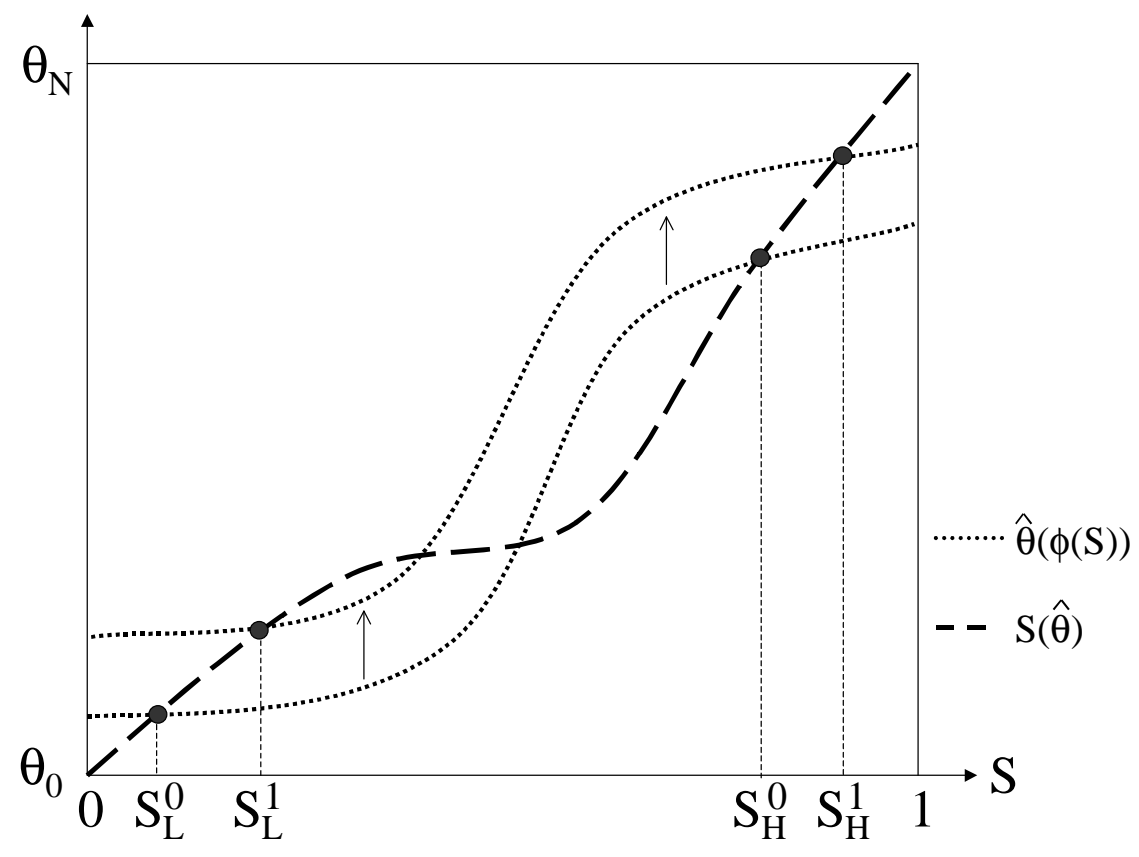

Figure 2: A $n$ increase in public insurance increases the steady state fraction of single individuals. 


\begin{tabular}{|c|c|c|c|c|}
\hline & \multicolumn{2}{|c|}{ Income Pooling } & \multicolumn{2}{|c|}{ Partner } \\
\hline & Coex. & Marg. Ex & Coex. & Marg. Ex \\
\hline Gender (male) & $\begin{array}{l}0: 028 \\
(0: 058)\end{array}$ & $0: 011$ & $\begin{array}{c}0: 138 \\
(0: 035)\end{array}$ & i $0: 052$ \\
\hline Age & $\begin{array}{l}0: 135 \\
(: 048)\end{array}$ & $0: 057$ & $\begin{array}{l}0: 270 \\
(0: 010)\end{array}$ & $0: 102$ \\
\hline Age Squared & i $0: 001$ & i 0:0006 & $\begin{array}{l}0: 003 \\
(0: 0001)\end{array}$ & i 0:001 \\
\hline Primary Education & $\begin{array}{l}0: 001 \\
(0: 065)\end{array}$ & 0:0006 & i $0: 133$ & i 0:051 \\
\hline University (male) & i $\begin{array}{c}0: 137 \\
(0: 059)\end{array}$ & i 0:057 & $\begin{array}{l}\text { i } 0: 030 \\
(0: 046)\end{array}$ & $0: 011$ \\
\hline University (female) & i $\begin{array}{c}0: 274 \\
(0: 064)\end{array}$ & i $0: 114$ & $\begin{array}{c}\text { i } 0: 299 \\
(0: 047)\end{array}$ & i 0:113 \\
\hline Self-employed & $\begin{array}{l}0: 042 \\
(0: 056)\end{array}$ & 0:017 & $\begin{array}{l}0: 043 \\
(0: 045)\end{array}$ & $0: 016$ \\
\hline Log Household-E arnings & i $0: 125$ & i 0:052 & i & $\mathrm{i}$ \\
\hline Household Size 3-4 & $\begin{array}{l}0: 319 \\
(0: 063)\end{array}$ & $0: 133$ & i & $\mathrm{i}$ \\
\hline Household Size $>4$ & $\begin{array}{l}0: 490 \\
(0: 098)\end{array}$ & $0: 205$ & $\mathrm{i}$ & $\mathrm{i}$ \\
\hline Divorced & i $0: 702$ & i 0:293 & $\begin{array}{c}\text { i } 0: 961 \\
(0: 042)\end{array}$ & i 0:365 \\
\hline Partner Divorced & $\begin{array}{c}\mathrm{i} \underset{(0: 063)}{0: 130} \\
0\end{array}$ & i 0:054 & i & $\mathrm{i}$ \\
\hline Religious Services & $\begin{array}{l}0: 044 \\
(0: 039)\end{array}$ & 0:018 & $\begin{array}{l}0: 016 \\
(0: 031)\end{array}$ & $0: 006$ \\
\hline Social Transfers $\%$ of GDP & i $\underset{(0: 007)}{0: 016}$ & i 0:007 & $\begin{array}{l}\text { i } 0: 007 \\
(0: 0057)\end{array}$ & i 0:003 \\
\hline Aggregate Divorce Rate & $\begin{array}{c}\text { i } 0: 075 \\
(0: 032)\end{array}$ & i 0:031 & i $0: 066$ & i 0:025 \\
\hline Female Partication Rate & $\begin{array}{c}\mathrm{i} \underset{(0: 005)}{0: 006} \\
\text { (0) }\end{array}$ & i 0:003 & $\begin{array}{l}0: 011 \\
(0: 002)\end{array}$ & 0:004 \\
\hline E mployment $\mathrm{P}$ rotection & $\begin{array}{l}0: 023 \\
(0: 027)\end{array}$ & 0:01 & $\begin{array}{c}0: 024 \\
(0: 023)\end{array}$ & $0: 009$ \\
\hline Constant & i $1: 366$ & & i $\begin{array}{l}5: 488 \\
(0: 221)\end{array}$ & \\
\hline $\begin{array}{l}\text { Censored obs: } 3058 \\
\text { Uncensored obs: } 4721\end{array}$ & $\begin{array}{l}\text { Wald Test of } \\
\log L=-69\end{array}$ & $\begin{array}{l}\text { f I ndep. E q.: } \\
49.75\end{array}$ & $\hat{A}^{2}(1)=3: 2$ & \\
\hline
\end{tabular}

Table 1: Exects on the probability of having a partner and the probability of pooling income given a partner. Estimation by bivariate probit with sample selection. Robust standard error in paranthesis. 